\title{
Crohn's Disease and Carcinoma of Colon
}

\author{
A. D. PERRETT,* M.B., CH.B., M.R.c.P. ; S. C. TRUELOVE,* M.D., F.R.C.P. \\ G. R. MASSARELLA, $\dagger$ M.B., CH.B., M.C.PATH.
}

[With Special Plate between Pages 466 and 467]

Brit. med. F., 1968, 2, 466-468

In a recent survey of Crohn's disease undertaken at the Radcliffe Infirmary three cases were encountered in which both carcinoma of the colon and Crohn's disease were present. As it is generally held that there is no association between these two diseases it seems important to report these cases and to discuss the possibility that a genuine association exists.

\section{Case 1}

A housewife was first admitted to the Radcliffe Infirmary in October 1949 at the age of 34 . She gave a history of eight months' diarrhoea and loss of weight, and two weeks' history of lower abdominal pain. She was emaciated and a mass was palpable in the right iliac fossa.

Investigations.-Haemoglobin $7.2 \mathrm{~g} . / 100 \mathrm{ml}$. Blood filmmarked iron-deficiency changes. Stools-repeatedly positive for occult blood, negative for pathogens, no acid-fast bacilli on culture. Barium enema showed an irregular filling defect of the caecum, together with narrowing of a short segment of the pelvic colon.

At operation in November 1949 the appearances were those of a malignant lesion of the caecum, to which the sigmoid colon and coils of terminal ileum were adherent, A right hemicolectomy, ileal resection, and sigmoid resection was carried out, with end-toend anastomosis of the left colon, and end-to-side ileotransverse colostomy.

The caecum contained a large soft carcinoma which had partially infiltrated the caecal wall. There were adhesions between caecum and overlying loops of ileum. Histologically the tumour was a moderately differentiated papillary adenocarcinoma. Microscopically, some adhesions were inflammatory in nature and others were neoplastic. A mixed inflammatory infiltrate within the caecum extended well beyond the limits of the tumour, and within this infiltrate were granulomatous foci containing giant cells. There were marked submucosal fibrous thickening and fibrous infiltration of pericolic fat, and fissures were present. Within the ileum there was again pronounced subserosal and submucosal fibrous thickening, and the submucosa contained patchy mixed inflammatory infiltrate, including moderate numbers of giant cells. Enlarged mesenteric lymph nodes showed marked reactive hyperplasia but no evidence of malignancy. In summary the changes were typical of Crohn's disease involving the caecum and ileum.

After the operation the patient developed a faecal fistula from the sigmoid resection site, but this eventually closed and she was discharged home three months after admission. She was readmitted four months later because the fistula had recurred. This was excised and the defect in the colon closed. She remained well for seven years.

She was admitted again in 1957 and an intraperitoneal abscess adjacent to the ileocolic anastomosis was drained. Numerous adhesions were divided at the time. She had persistent diarrhoea after this operation and was readmitted a few months later with a fistula-in-ano, a fissure-in-ano, and an ischiorectal abscess. These were dealt with surgically and she was discharged considerably improved.

She was next admitted in November 1958 with a small-intestinal obstruction. Laparotomy revealed a mass at the site of the ileocolic

\footnotetext{
* Nuffield Department of Clinical Medicine, the Radcliffe Infirmary,

t Department of Morbid Anatomy, the Radcliffe Infirmary, Oxford.
}

anastomosis, and this was resected. The sections of both large and small bowel were typical of Crohn's disease.

She was admitted three times in 1960 with recurrent fistulae-inano. Barium meal and follow-through examination showed a recurrence of Crohn's disease in the terminal ileum about $10 \mathrm{~cm}$. in length (Special Plate, Fig. 1). This was resected, the diseased segment being histologically consistent with Crohn's disease.

She was again admitted a year later with an eight-month history of loss of weight and diarrhoea. She had steatorrhoea with a faecal fat excretion of $16.7 \mathrm{~g} . / 24$ hours and evidence of multiple deficiencies. She was given full replacement therapy and intermittent corticosteroids, and has remained well since then apart from fistulae-in-ano in 1964 and 1965 which were treated surgically.

She was last seen in October 1967, when she was very well apart from mild diarrhoea.

\section{Case 2}

A 67-year-old widowed housewife was first admitted to the Radcliffe Infirmary in November 1962. She complained of abdominal pain of eight weeks' duration and of intermittent bloodstreaked diarrhoea for six weeks. On examination the only positive findings were emaciation and tenderness and guarding in the left iliac fossa.

Investigations.-Haemoglobin 11.1 g./100 ml. Blood filmmarked hypochromia, W.B.C. $11,000 / \mathrm{cu}$. mm., with a polymorphonuclear leucocytosis. Stools-repeatedly positive for occult blood. Barium enema showed ulceration of the left side of the colon with a stricture of the sigmoid colon (Special Plate, Fig. 2).

Laparotomy in January 1963 revealed a large mass in the sigmoid colon which was thought to be due to diverticulitis. This was resected and a proximal transverse colostomy made.

The resected sigmoid colon measured $20 \mathrm{~cm}$. and contained a carcinoma $6 \mathrm{~cm}$. in diameter (Special Plate, Fig. 3). The remainder of the colon showed thickening of the wall and numerous areas of ulceration. Histologically the tumour was a well-differentiated adenocarcinoma, and sections taken adjacent to and distant from the tumour showed marked submucosal and subserosal fibrous thickening, widespread chronic inflammatory cell infiltrate, and numerous epithelioid granulomata in all layers of the bowel wall (Special Plate, Figs. 4 and 5). The microscopical picture was characteristic of Crohn's disease.

She made an uneventful recovery and was discharged in February 1963, the colostomy being closed three months later.

She was readmitted seriously ill in February 1964, having had bloody diarrhoea for six weeks. She was emaciated, pyrexial, and dehydrated. Her fingers were noted to be clubbed and there was marked tenderness in the left iliac fossa.

Investigations.-Haemoglobin $10.2 \mathrm{~g} . / 100 \mathrm{ml}$; W.B.C. 10,400, with a polymorphonuclear leucocytosis ; serum potassium $2.6 \mathrm{mEq} /$ litre. One-stage prothrombin value was $49 \%$ of normal. Barium enema showed extensive colonic ulceration and a sinus leading from the upper part of the descending colon into a large pocket beneath the left lateral abdominal wall near the iliac crest.

Two days after admission she developed a swelling in the left thigh. This was incised and a mixture of pus and fluid faeces drained from it. She was treated with antibiotics, blood transfusion, and intravenous feeding with benefit. Laparotomy was performed in April 1964, when an extensive chronically infected area was found in the descending colon just above the site of the previous anastomosis; this was the origin of the external fistula. A subtotal 


\section{A. D. PERRETT ET $A L$ : CROHN'S DISEASE AND CARCINOMA OF COLON}
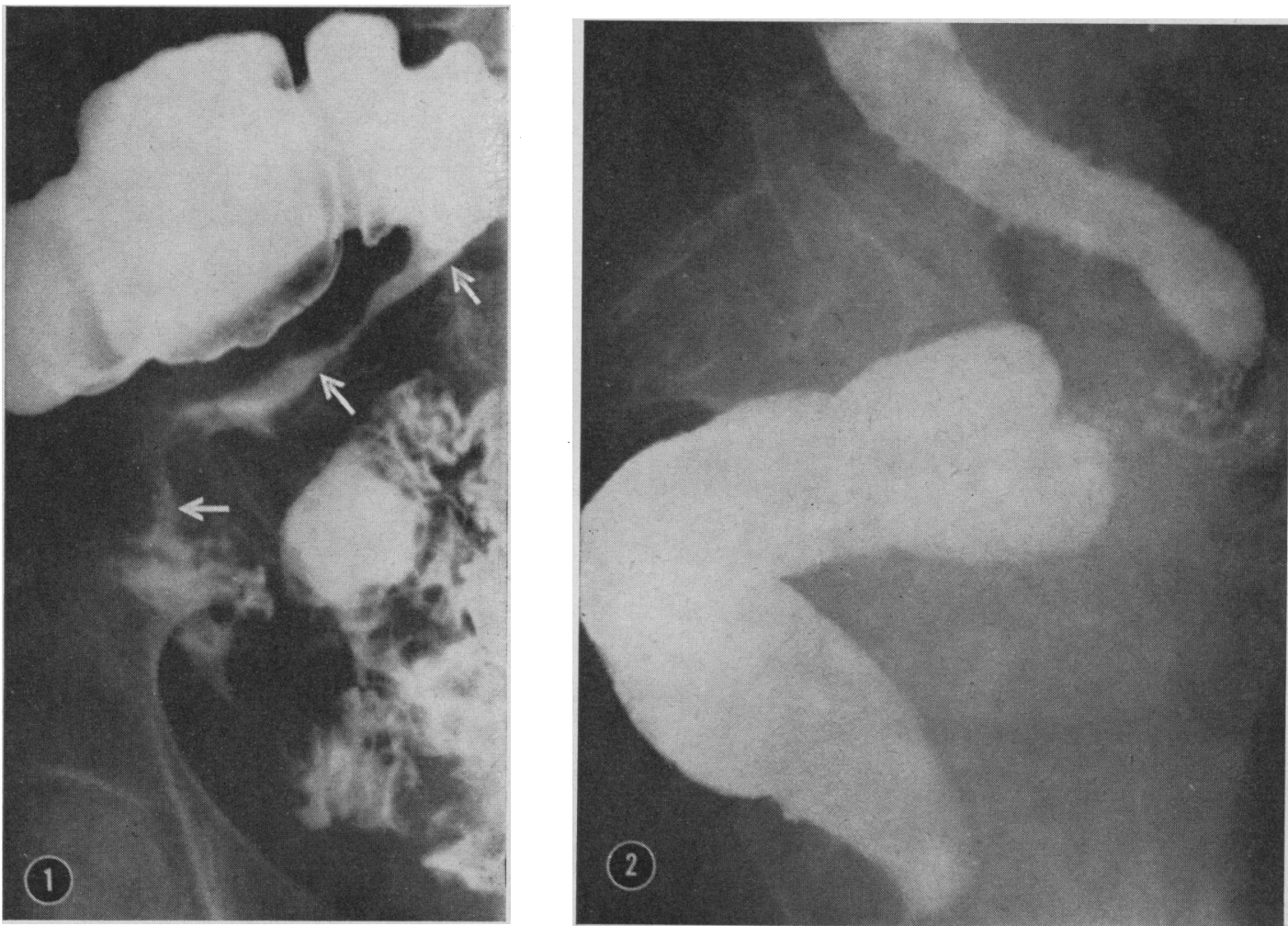

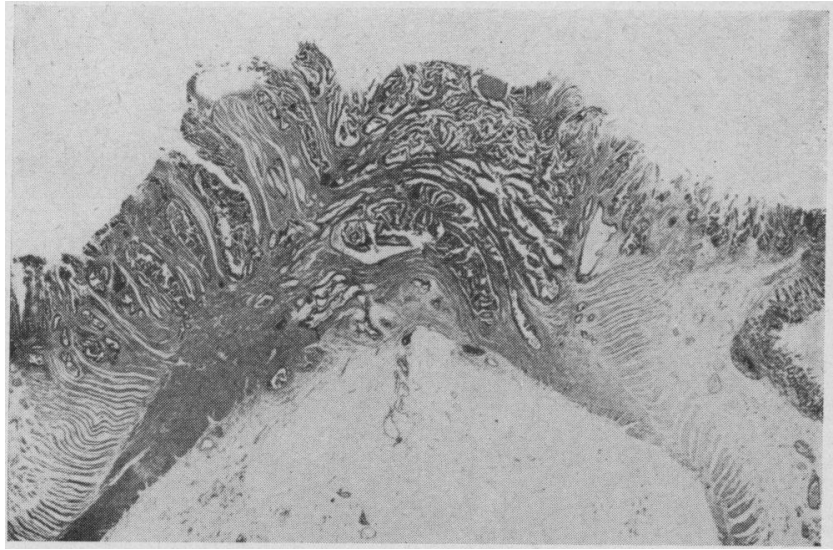

Fig. 3.-Case 2. Low-power view of the first carcinoma of the colon.

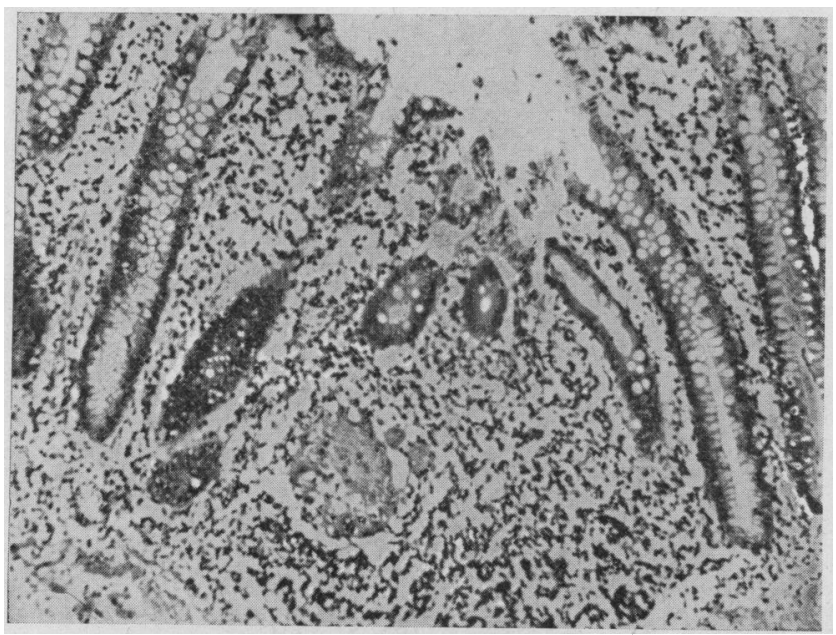

FIG. 4.-Case 2. Profuse inflammatory cell infiltration and granuloma in the colonic mucosa.
FIG. 1.-Case 1. Barium follow-through examination showing recurrence of terminal ileum (arrowed) after previous resection and ileotransverse colostomy.

FIG. 2.-Case 2. Barium enema showing ulceration of the left side of the colon, together with a stricture of the sigmoid colon.

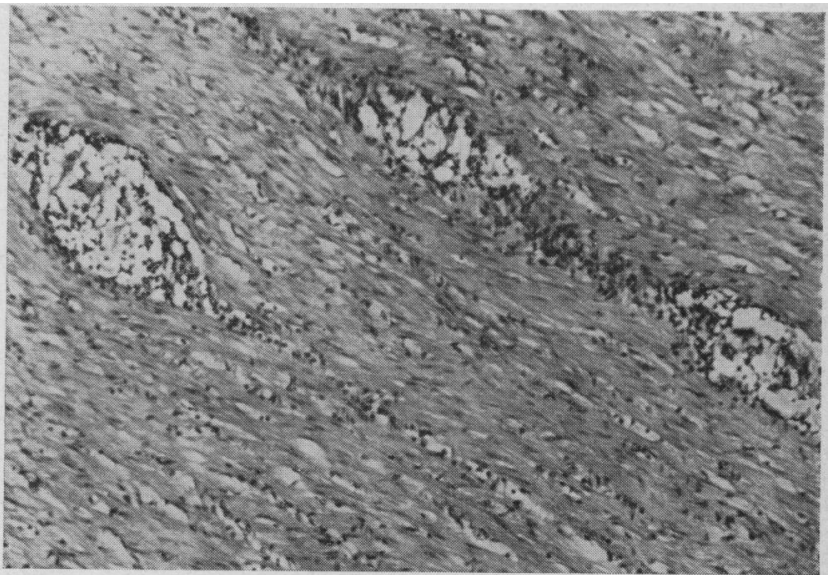

Fig. 5.-Case 2. Granulomata in the muscle layer of the bowel wall.

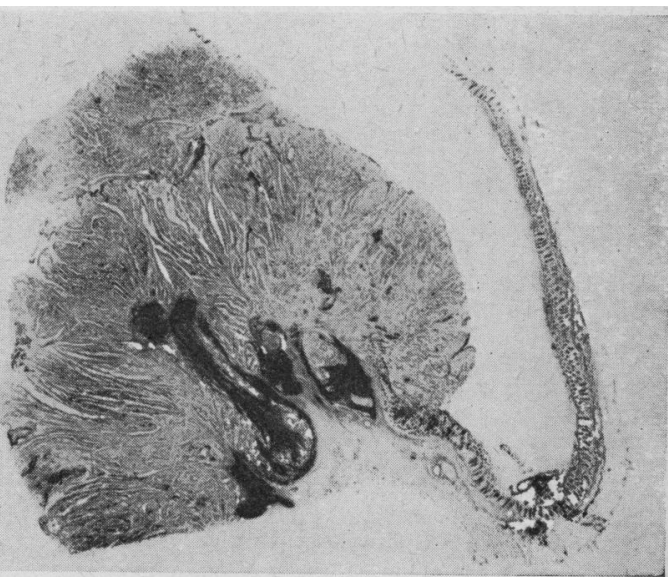

FIG. 6.-Case 3. Low-power view of carcinoma of the colon. 


\section{A. D. PERRETT ET $A L$. : CROHN'S DISEASE AND CARCINOMA OF COLON}

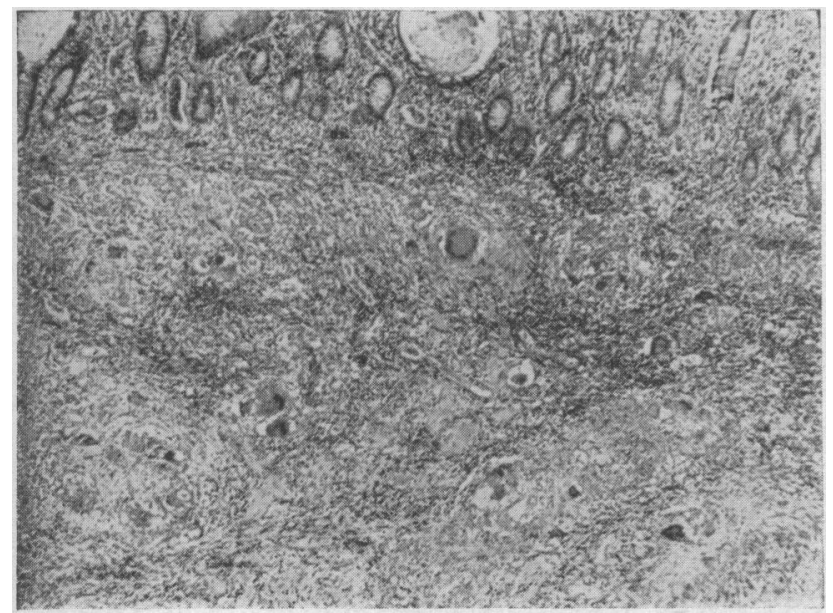

Fig. 7.-Case 3. Heavy inflammatory infiltrate, submucosal thickening, and profuse epithelioid granulomata in the bowel wall.

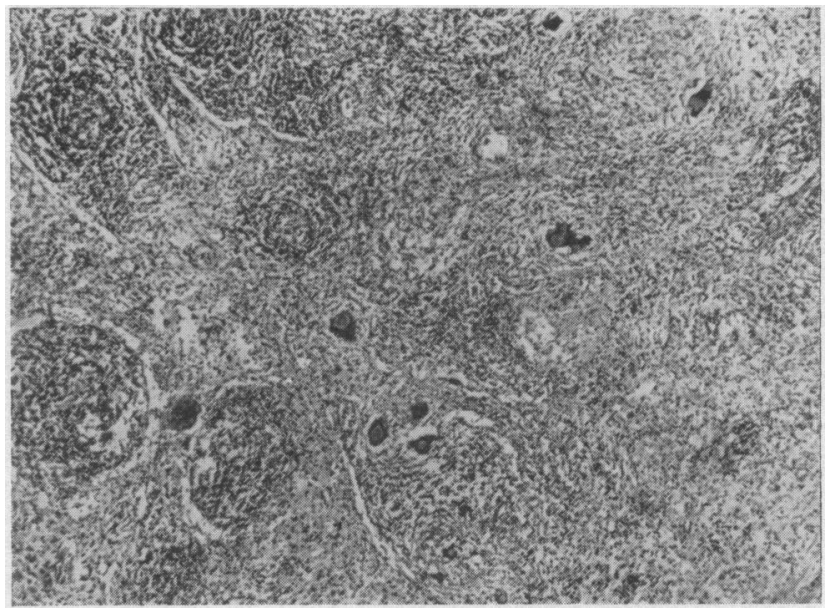

Fig. 8.-Case 3. Lymph node showing profuse granulomata and disorganized architecture.

\section{P. RICHARDS ET $A L .:$ RECOVERY FROM ACUTE RENAL FAILURE}
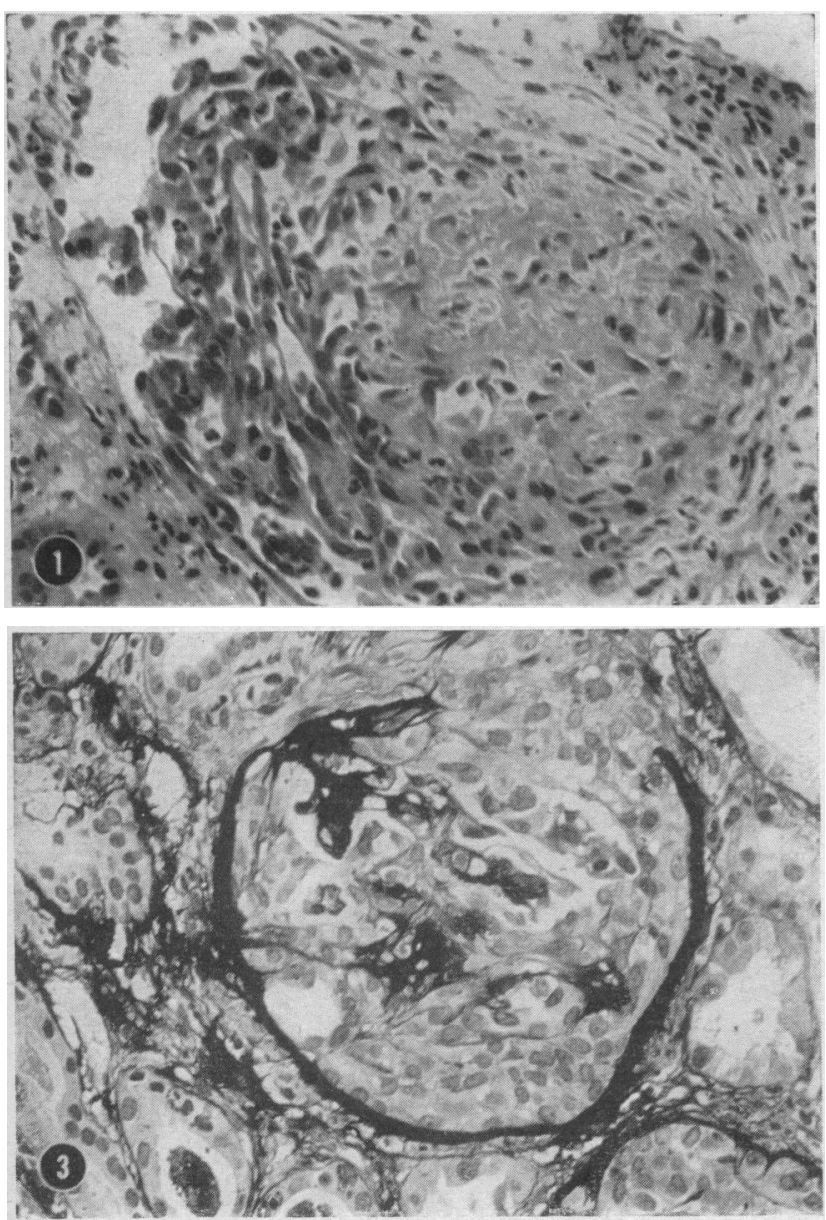

FIg. 1.-Case 1. Glomerulus showing a totally disorganized area A few capillary loops showing proliferation and a polymorph exudate are present on left side of picture. (H. and $\mathrm{E}$. $\times 288$.)

FIg. 2.-Case 1. Interlobar artery from kidney at necropsy, showing break in elastic lamina. (Elastic van Gieson. $\times 72$.)

Fig. 3.-Case 2. Disorganized glomerulus. The intensely black areas are remnants of basement membrane. There is an extensive proliferative capsulitis with a break in Bowman's capsule. (Periodicacid silver methenamine. $\times 288$.)

Fig. 4.-Case 3. Severe proliferative and exudative glomerulitis. (Periodic-acid Schiff. $\times 288$.)

FIg. 5.-Case 3. One of the capillary tufts (arrowed) showing an area of fibrinoid necrosis. (Periodic-acid silver methenamine.
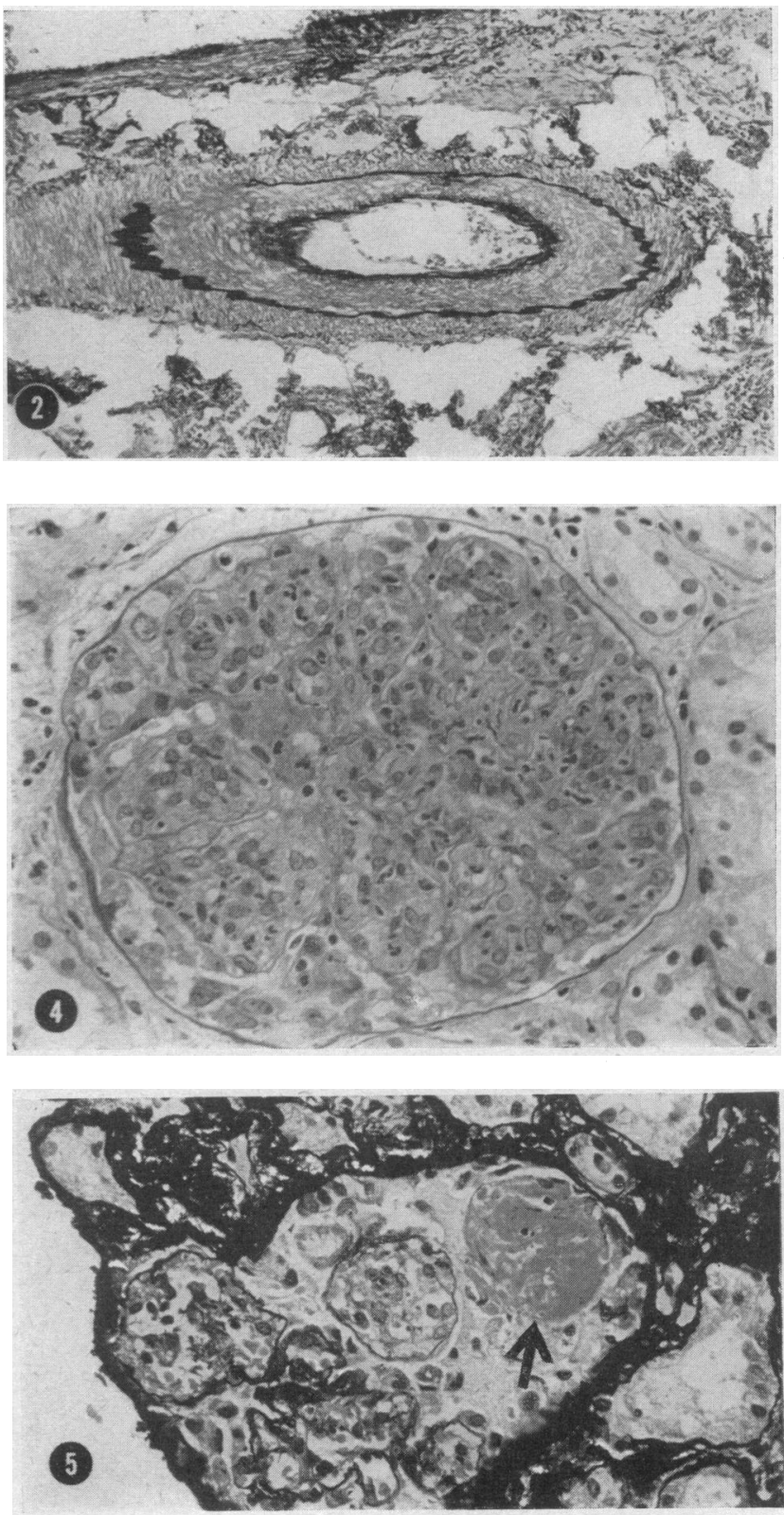
colectomy with ileostomy was performed and the rectal stump was oversewn.

Histological examination of the excised specimen showed Crohn's disease of the entire colon, a well-differentiated adenocarcinoma of the caecum, and a small separate area of intramucosal carcinoma in the transverse colon.

She recovered satisfactorily and when seen in August 1964 was feeling extremely well. However, sigmoidoscopy showed a grossly inflamed rectum. She was advised to have the rectal stump removed, but refused and did not attend the hospital again.

She died at home in August 1966. The cause of death was given as intestinal obstruction due to carcinoma, but post-mortem examination was not carried out.

\section{Case 3}

A housewife was first admitted to the Radcliffe Infirmary in June 1963 at the age of 72 . She complained of severe pain in the right iliac fossa of three weeks' duration. A tender mobile irregular mass was palpable in the right iliac fossa.

Investigations.-Haemoglobin $12.3 \mathrm{~g} .100 \mathrm{ml}$. W.B.C. 5,000. E.S.R. $62 \mathrm{~mm}$. in one hour. Urine normal. Stools positive for occult blood. Intravenous pyelogram normal. No barium studies were carried out. At laparotomy a massive growth was found in the caecum. A right hemicolectomy with side-to-side ileotransverse colostomy was performed.

Histological examination showed the mass to be a moderately well differentiated papillary adenocarcinoma (Special Plate, Fig. 6). Sections of the adjacent colon and caecum revealed extensive granulomatous and inflammatory changes characteristic of Crohn's disease (Special Plate, Fig. 7). The excised regional lymph nodes showed similar profuse epithelioid granulomata with disorganization of the lymph node architecture (Special Plate, Fig. 8).

She recovered well and was discharged home asymptomatic apart from moderate diarrhoea which had developed postoperatively. She was seen regularly at a follow-up clinic and remained well apart from the persistent diarrhoea.

In February 1967 her haemoglobin was 11.0 g. $/ 100 \mathrm{ml}$. and the serum iron only $56 \mu \mathrm{g} . / 100 \mathrm{ml}$. ; she was accordingly treated with oral iron.

She was readmitted in June 1967 for investigation of a megaloblastic anaemia, the haemoglobin having fallen to $7.5 \mathrm{~g} .1100 \mathrm{ml}$. She gave a good history of steatorrhoea, having each day 5 to 10 loose light-coloured stools which floated. There was no passage of blood or mucus. For six months previously she had noticed coldness and tingling of her finger-tips, easy bruising, and weight loss of $7 \mathrm{lb}$. (3.2 kg.). She was wasted and apathetic. The abdomen was distended and there was pitting oedema up to the knees. There were no signs of peripheral neuropathy or of posterior column lesions. There was mild generalized lymphadenopathy.

Investigations.-Marrow megaloblastic. Serum vitamin $\mathbf{B}_{19}$ $25 \mu \mu \mathrm{g} . / \mathrm{ml}$. (low), $B_{12}$ uptake $4 \%$ (low). Serum folate $11 \mathrm{~m} \mu \mathrm{g} . / \mathrm{ml}$. (normal). Gastric acid secretion low. Intrinsic factor output high. Liver function tests normal. Serum proteins normal. Serum calcium $4.2 \mathrm{mEq} / \mathrm{l}$. (low). Phosphate and alkaline phosphatase normal. Stools repeatedly positive for occult blood. Barium meal and follow-through examination showed an abnormal distal small intestine. A repeat barium follow-through examination and a

Frequency of Carcinoma of Colon Occurring in Association with Crohn's Disease in Other Series

\begin{tabular}{|c|c|c|c|c|}
\hline \multirow[b]{2}{*}{ Authors } & \multicolumn{2}{|c|}{$\begin{array}{l}\text { No. of Cases } \\
\text { of Crohn's Discase }\end{array}$} & \multicolumn{2}{|c|}{ Carcinoma } \\
\hline & $\begin{array}{l}\text { Total } \\
\text { No. }\end{array}$ & $\begin{array}{l}\text { No. With } \\
\text { Colonic } \\
\text { Involvement }\end{array}$ & No. & Site \\
\hline 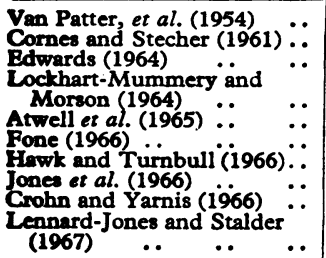 & $\begin{array}{r}600 \\
131 \\
224 \\
\\
75 \\
212 \\
41 \\
87 \\
96 \\
1,291\end{array}$ & $\begin{array}{l}222(37 \%) \\
94(72 \%) \\
<20 \% \\
75 \\
62(29 \%) \\
77 \\
87 \\
96 \\
291(22 \cdot 5 \%) \\
0 \\
0\end{array}$ & $\begin{array}{l}1 \\
2 \\
0 \\
0 \\
3 \\
0 \\
1 \\
0 \\
2 \\
1\end{array}$ & $\begin{array}{l}\text { Colon } \\
\text { Rectum } \\
\text { Colon } \\
\text { Colon } \\
\text { Colon } \\
\text { Rectum }\end{array}$ \\
\hline
\end{tabular}

barium enema, however, failed to demonstrate any definite abnormality in the small or large bowel.

She was treated with supplements and discharged home on maintenance therapy. At follow-up in September 1967 she was very well apart from moderate diarrhoea. The haemoglobin at that time was $13.7 \mathrm{~g} . / 100 \mathrm{ml}$. and serum calcium $4.8 \mathrm{mEq} / 1$.

\section{Discussion}

There is unequivocal pathological evidence that all three patients suffered from Crohn's disease and carcinoma of the colon. They were similar in that they all presented with a carcinoma and the Crohn's disease was an additional pathological finding. Additional pathological confirmation was obtained from subsequent operation specimens in the first two patients. The third patient appears to have had a clinical recurrence of Crohn's disease, but decisive objective evidence is at present lacking.

Since 1938154 patients attending the Radcliffe Infirmary have been diagnosed as suffering from Crohn's disease. Of these, 82 have had colonic involvement. This represents a higher proportion of colonic Crohn's disease than has been found in most other series, but this simply reflects the special interest in large-bowel disorders in this hospital.

Even if the whole series is considered, three examples of carcinoma of the colon in 154 patients are more than would be expected in a random sample of the population. If only those patients with evidence of colonic involvement are considered ( 82 patients), the frequency of carcinoma becomes $3.7 \%$, which corresponds closely to the figure of $3.5 \%$ in 624 cases of ulcerative colitis seen at the Radcliffe Infirmary from 1938 to 1963 (Edwards and Truelove, 1964).

The literature dealing with carcinoma occurring in association with Crohn's disease is scanty. So far as carcinoma of the small intestine is concerned we have found a number of individual case reports (Bersack et al., 1958 ; Buchanan et al., 1959 ; Ginzburg et al., 1956 ; Kornfeld et al., 1957 ; Weingarten et al., 1959 ; Weingarten and Weiss, 1960 ; Zisk et al., 1960). In nearly all these cases the Crohn's disease had been diagnosed several years before the occurrence of the carcinoma.

Sporadic examples of carcinoma of the colon have appeared in published series of Crohn's disease, as shown in the Table. It will be seen that the overall frequency is low. When only those cases with evidence of colonic involvement are considered the frequency becomes higher, but is not striking. The exception is the series from Leeds reported by Atwell et al. (1965), who had three cases of carcinoma occurring in 62 patients with colonic Crohn's disease, a frequency of $4.8 \%$.

There is a particular reason why further examination of the question of a possible association between Crohn's disease and carcinoma of the colon is highly desirable. Though it has been generally recognized that the colon may be involved in Crohn's disease when the terminal ileum is affected, either in continuity (so-called "ileocolitis") or as a "skip" lesion remote from the ileum, it is only in recent years that primary involvement of the colon has come to be accepted as a distinct clinical and pathological entity. The definitive article on this topic was that by Lockhart-Mummery and Morson (1960), and since then there have been other important contributions, such as those by Cornes and Stecher (1961) and LockhartMummery and Morson (1964). In the U.S.A. a similar recognition has taken place, though the term "granulomatous colitis" is usually preferred to primary Crohn's disease of the colon. The apparently low risk of carcinoma of the colon in this disease has been commented on by several writers, and Janowitz and Present (1966) have remarked that "toxic dilatation and carcinoma have yet to be described in this form of inflammatory disease of the large bowel." 
While the facts do not permit us to assert that there is a definite association between these two diseases, there is sufficient evidence to call for a further close examination of the question.

\section{Summary}

Among 154 patients with Crohn's disease attending the Radcliffe Infirmary since 1938 there have been three with carcinoma of the colon. Case histories of these three patients are given.

If only the cases of Crohn's disease with evidence of colonic involvement are considered ( 82 patients) the frequency of carcinoma of the colon in this series is $3.7 \%$.

In reported series dealing with colonic disease, carcinoma of the colon has appeared to be infrequent except in one series with a frequency of $4.8 \%$.

The question of a possible association between Crohn's disease of the colon and carcinoma deserves further examination.
REFERENCES

Atwell, J. D., Duthie, H. L., and Goligher, J. C. (1965). Brit. J. Surg., $52,966$.

Bersack, S. R., Howe, J. S., and Rehak, E. M. (1958). Gastroenterology, 34, 703

Buchanan, D. P., Huebner, G. D., Woolvin, S. C., North, R. L., and Novack, T. D. (1959). Amer. 'f. Surg., 97, 336.

Cornes, J. S., and Stecher, M. '(1)61). Gut, 2, 189.

Crohn, B. B., and Yarnis, H. (1966). 7. Mt Sinai Hosp., 33, 503.

Edwards, F. C., and Truelove, S. C. (1964). Gut, 5, 1.

Edwards, H. (1964). 7. roy. Col. Surg. Edinb., 9, 115.

Fone, D. J. (1966). Med. F. Aust., 1, 8\$5.

Ginzburg, L., Schneider, K. M., Dreicon, D. H., and Levinson, C. (1956). Surgery, 39, 347

Hawk, W. A., and Turnbull. R. B. (196: Gastroenterology, 51, 802.

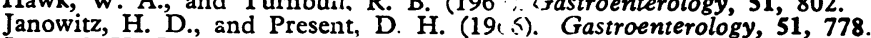

Jones, J. H., Lennard-Jones, J. E., and Lockhart-Mummery, H. E. (1966). Gut, 7, 448.

Kornfeld, P., Ginzburg, L., and Adlersburg, D (1957). Amer. F. Med., 23, 493 .

Lennard-Jones, J. E., and Stalder, G. A. (1967). Gut, 8, 332.

Lockhart-Mummery, H. E., and Morson, B. C. (1960). Gut, i, 87.

Lockhart-Murnmery, H. E., and Morson, B. C. (1964). Gut, 5, 493.

Van Patter, W. N., Bargen, J. A., Dockerty, M. B., Feldman, W. H., Mayo, C. W., and Waugh, J. M. (1954). Gast: :enterology, 26, 347,

Weingarten, B., Parker, J. G., Chazen, E. M., and Jac.uvson, H. G. (1959). Arch. Surg., 78, 483

Weingarten, B., and Weiss, J. (1960). Amer. 7. Gastruent., 33, 203.

Zisk, J., Shore, J. M., Rossoff, L., and Friedman, N. 8. ::960:. Surgery, 47, 970 .

\title{
Haemodynamic Effects of Lignocaine in Acute Myocardial Infarction
}

\author{
MARY STANNARD,* M.B., B.S., M.R.A.C.P.; GRAEME SLOMAN, $†$ M.B., B.SC., M.R.C.P., M.R.C.P.EI: ; F.R.A.C.F \\ LINNET SANGSTER $\ddagger$
}

Lignocaine (Xylocaine, Lidocaine) is now widely accepted as an antiarrhythmic agent, particularly in the management of ventricular tachycardia and ventricular ectopic beats occurring as complications of acute myocardial infarction (Frieden, 1965 ; Bedynek et al., 1966; Lown et al., 1967). Lignocaine is regarded as producing a low incidence of drug complications (Lown et al., 1967), but little information is available on its haemodynamic effects in patients with acute myocardial infarction.

\section{Methods and Materials}

Eight patients were studied, being selected from those admitted to the Coronary Care Unit of the Royal Melbourne Hospital with transmural myocardial infarction which had occurred within the previous 24 hours. Contraindications for admission to the study were cardiogenic shock or complete heart block. All the patients were men with an age range from 49 to 63 years, mean 57.5 years. They were classified as having had mild or severe infarction according to the criteria of Robinson et al. (1964), and on this basis three were mild and five severe cases. Papaveretum (Omnopon) was used as the analgesic where indicated, and all patients received oxygen by means of a face mask. None of the patients was studied until pain had been completely relieved; the nature of the study was explained to them and they were caused no obvious distress.

Fine plastic tubing (P.E.50) was introduced into the right median cubital vein through an 18-gauge thin wall needle and

- Research Assistant, Cardiac Department, the Royal Melbourne Hospital. Grant-in-aid No. G.428, National Heart Foundation of pital. Astralia.

t Director, Cardiac Laboratory, the Royal Melbourne Hospital.

₹ Cardiac Technician, Cardiac Department, the Royal Melbourne Hospital. Supported by a grant from the Felton Bequest. flow-guided catheterization performed as described by Dotter and Straube (1962). Pulmonary artery or right ventricular pressure and right atrial pressure were ascertained. The brachial artery was cannulated with a nylon cannula, ${ }^{1}$ using the Seldinger technique. Pressures were recorded by means of a Sanborn differential transformer transducer (267A) and a Sanborn 2-channel direct writing system (296 T.C.). Pressures were recorded with the patient lying in bed with the head raised on one pillow, the manubrium sterni being the point of reference.

Cardiac output was determined by a dye-dil:tion method, 은 indocyanine green (Cardio-green) being used. The dye solution N was injected rapidly into the right atrium via the venous catheter, and arterial blood was withdrawn from the brachial artery at a constant rate by a motor-driven pump. Recordings were obtained through a Waters X.301 densitometer and a Moseley 7035A X-Y recorder. The cardiac output was calculated from the curves so obtained, using a planimetric method (Dalby et al., 1967). The heart rate was determined by an electrocardiogram recorded simultaneously with the cardiac output studies.

Systemic blood pressure and duplicate estimations of cardiac output and heart rate were measured at rest, immediately after and 10 minutes after the intravenous injection of $100 \mathrm{mg}$. of lignocaine. In four cases blood pressure was monitored continuously during the administration of lignocaine and at inter- $\bar{q}$ vals over the next 10-minute period. Pulmonary artery or right $尺$ ventricular pressure was measured at rest and at the completion of the study, approximately 15 minutes after the administration of lignocaine. The drug was injected over a five-minute period, the completion of the injection being taken as zero time.

\footnotetext{
${ }^{1}$ Portex nylon intravenous cannula, length 12 in. $(30 \mathrm{~cm}$.), outer diameter 0.052 in. $(1.3 \mathrm{~mm}$.).
} 